\title{
El reconeixement del present històric a l'educació primària. Cap a un ensenyament-aprenentatge interdiscilplinari dels temps verbals
}

\author{
Mariona Casas-Deseures \\ Universitat de Vic \\ mariona.casas@uvic.cat
}

Resum: Aquest article parteix d'una recerca sobre didàctica de la llengua que gira entorn del reconeixement del valor retrospectiu del present (present històric) per part d'alumnes de $3 r$ i Gè d'educació primària. Els resultats mostren que els participants recorren a la seva experiència, al coneixement del món $i$ al coneixement que tenen sobre els marcadors temporals per resoldre la tasca que se'ls proposa. A les conclusions es reflexiona sobre la necessitat de plantejar l'ensenyament-aprenentatge dels temps verbals des d'un punt de vista interdisciplinari.

Paraules clau: Didàctica de la llengua, educació primària, present històric, temps verbals.

Abstract: This article is based on a research in language teaching which is about the recognition of the retrospective usage of the simple present tense (historical present) by students of $3 \mathrm{rd}$ and 6 th of primary education. The results show that in order to solve the task students focus on their own experience, their world knowledge and their knowledge about temporal modifiers. The conclusions propose to teach verb tenses from an interdisciplinary perspective.

Keywords: Language teaching, primary education, simple present tense, verb tenses.

\section{Marc de la recerca}

El verb és una de les nocions lingüístiques més complexes, ja que en la nostra llengua (i en moltes altres) articula l'expressió de la temporalitat a través del sistema de temps verbals. Aquest sistema permet situar els esdeveniments prenent com a referència el moment de l'enunciació (passat, present, futur), però els significats temporals que el verb pot arribar a expressar superen de llarg els tres temps bàsics. Des del punt de vista didàctic, el verb s'aborda sobretot morfològicament i pràcticament no s'atén la relació entre les formes verbals i els seus usos, plantejament que implicaria mobilitzar altres tipus de coneixements, no solament els estrictament lingüístics. En aquest article, s'hi presenten els resultats d'una recerca que justament posa en relleu quina mena de coneixements activen els alumnes de $3 r$ i 6è per reconèixer el present històric, i es formulen algunes implicacions didàctiques per a l'ensenyament-aprenentatge dels temps verbals a l'educació primària.

Per emmarcar aquesta recerca, ens remetrem, succintament, a la noció de temporalitat i al tractament del verb i del temps al currículum d'educació primària. El concepte de temps és conegut, sobretot, gràcies a Piaget, que va portar a terme nombroses recerques per entendre com els infants desenvolupen aquesta noció. Malgrat que 
ningú no dubta de les seves aportacions, ${ }^{1}$ estudis posteriors li critiquen una visió excessivament psicològica, que es limita a tractar el temps com a categoria del pensament (Perret-Clermont i Lambolez, 2005). Justament la present recerca se situa en la perspectiva sociocultural, segons la qual l'apropiació de les referències temporals es construeix socialment. Des d'aquest paradigma, partim d'investigacions d'influència vigotskiana, com la de Tartas (2009), que analitza les eines simbòliques que els infants desenvolupen per poder estructurar el temps. Tartas demostra que els infants construeixen les eines lingüístiques que els permeten donar sentit al temps d'acord amb el seu desenvolupament cognitiu, les rutines experiencials i els aprenentatges escolars.

\section{El verb i el temps al currículum d'educació pri- mària}

En relació amb els aprenentatges escolars, fixem-nos en els continguts d'aprenentatge relacionats amb la categoria gramatical verb que prescriu el marc curricular vigent a l'educació primària a Catalunya. A l'àmbit de llengües (Decret $142 / 2007$, p. $30-73$ ), dins el bloc "Coneixements del funcionament de la llengua i del seu aprenentatge", a cicle inicial l'únic contingut es refereix a la "introducció a la terminologia gramatical", dins del qual s'especifiquen tres categories gramaticals, entre les quals el verb.

A cicle mitjà es passa a l'ús dels conceptes introduïts a cicle inicial i al seu reconeixement en un text, i s'hi afegeix la diferenciació dels tres temps bàsics (present, passat i futur). Finalment, a cicle superior, els continguts giren entorn d'aspectes sintàctics (el reconeixement del grup verbal i la concordança) i del reconeixement dels trets que distingeixen un verb com a categoria gramatical.

1 Piaget va publicar diversos treballs sobre la noció de temps, però destaquem, sobretot, Le développement de la notion de temps chez l’enfant (1946; versió en castellà, 1978).
La taula següent presenta els continguts d'aprenentatge classificats segons els tres cicles educatius:

Taula 1. Continguts d'aprenentatge de la categoria gramatical verb al currículum (àmbit de llengües)

\begin{tabular}{|c|c|}
\hline $\begin{array}{l}\text { Cicle } \\
\text { inicial }\end{array}$ & $\begin{array}{l}\text { - "Introducció a la terminologia gra- } \\
\text { matical: nom, verb, oració, masculí, } \\
\text { femení, article, singular, plural" (p. } \\
41 \text { ) }\end{array}$ \\
\hline $\begin{array}{l}\text { Cicle } \\
\text { mitjà }\end{array}$ & $\begin{array}{l}\text { "Ús de terminologia gramatical: nom, } \\
\text { verb, oració, masculí, femení, article, } \\
\text { singular, plural, passat, present, fu- } \\
\text { tur" (p. 50) } \\
\text { "Reconeixement d'articles, connec- } \\
\text { tors, noms, adjectius i verbs en un } \\
\text { text. Diferenciar els temps verbals } \\
\text { (passat, present i futur) en enunciats" } \\
\text { (p. 50) }\end{array}$ \\
\hline $\begin{array}{l}\text { Cicl } \\
\text { supe }\end{array}$ & $\begin{array}{l}\text { "Reconeixement en un enunciat del } \\
\text { grup nominal i del grup verbal: nom } \\
\text { i complements, verb i complements. } \\
\text { Deducció del funcionament de la } \\
\text { concordança" (p. 61) } \\
\text { "Reconeixement dels trets bàsics que } \\
\text { distingeixen un verb com a categoria } \\
\text { gramatical: temps i persona, aspectes } \\
\text { perfectius i imperfectius" (p. 61) }\end{array}$ \\
\hline
\end{tabular}

Així, doncs, al marc curricular vigent, el verb hi és introduït com a categoria gramatical a cicle inicial, mentre que els cicles mitjà i superior se centren en el reconeixement d'aquesta categoria, des del punt de vista dels tres temps verbals bàsics (cicle mitjà) i de les seves característiques morfològiques i sintàctiques (cicle superior).

Però el concepte de temporalitat també s'aborda des de l'àrea de Coneixement del Medi Natural, Social i Cultural (p. 74-93), que desplega diversos continguts relacionats amb el temps, agrupats en l'apartat "Canvis i continuïtats en el temps", que es presenten a la taula següent, classificats també segons els tres cicles educatius: 


\begin{tabular}{|l|l|}
\hline $\begin{array}{l}\text { Taula 2. Continguts d’aprenentatge sobre l'expressió } \\
\text { del temps (àrea de Coneixement del Medi Natural, } \\
\text { Social i Cultural) }\end{array}$ \\
\hline $\begin{array}{l}\text { Cicle } \\
\text { inicial }\end{array}$ & $\begin{array}{l}\text { "Ús de les nocions bàsiques de temps } \\
\text { (abans/després, passat/present/ futur, } \\
\text { durada) i de les unitats de mesura } \\
\text { bàsiques (dia, setmana, mes i any)" } \\
\text { (p. 83) }\end{array}$ \\
\hline $\begin{array}{l}\text { Cicle } \\
\text { mitjà }\end{array}$ & $\begin{array}{l}\text { "Ús d'unitats de mesura temporal i } \\
\text { aplicació de les nocions de canvi i } \\
\text { continuïtat en l'anàlisi de l'evolució } \\
\text { d'algun aspecte de la vida quotidiana } \\
\text { al llarg del temps, comparant cultu- } \\
\text { res allunyades en lespai o el temps" } \\
\text { (p. 86) }\end{array}$ \\
\hline $\begin{array}{l}\text { "Comprensió del temps cronològic } \\
\text { i ús de representacions gràfiques } \\
\text { per situar fets i etapes de l'evolució } \\
\text { històrica" } \\
\text { "Ús de la periodització convencio- } \\
\text { naperior i de les convencions de datació } \\
\text { i identificació de la durada, simul- } \\
\text { taneïtat i successió desdeveniments } \\
\text { històrics" (p. 90-91) }\end{array}$ \\
\hline
\end{tabular}

Així, doncs, en el cas de làrea de Coneixement del Medi Natural, Social i Cultural, observem que l'expressió del temps es desplega en relació amb la comprensió del món i que sexpliciten termes com els que designen els tres temps bàsics (present, passat, futur), nocions bàsiques de temps (abans/després, etc.), unitats de mesura temporal o altres com temps cronologic, simultaneïtat, successió.

Constatem, doncs, que des del punt de vista curricular, a l'educació primària el concepte de temps és poc present a l’àrea de llengua i es desplega, sobretot, a l'àrea de Coneixement del Medi Natural, Social i Cultural, que és des d'on es treballa la temporalitat.

Tancarem aquest apartat referint-nos als resultats d'algunes recerques sobre l'ensenyament del verb i dels temps verbals a l'educació primària. Les investigacions més recents reclamen que el verb, a l'escola, s'abordi des d'una perspectiva pluridimensional (Casas, 2012a; Gourdet, 2010; Lepoire-Duc i Ulma, 2010), és a dir, integrant els aspectes morfològics, semàntics, sintàctics i pragmàtics d'aquesta noció. Aquesta perspecti- va permetria construir el coneixement sobre els temps verbals d'acord amb la presència i funció d'altres elements lingüístics que també expressen la temporalitat dels enunciats. Des de la psicolingüística, Klein (2009) sosté que les llengües han desenvolupat almenys sis dispositius per ancorar temporalment els enunciats lingüístics: tres estan relacionats amb el verb (el temps verbal, l'aspecte morfològic i l'aspecte lèxic) i els altres tres són els adverbis temporals, les partícules temporals (presents en algunes llengües, com el xinès) i l'estructura intrínseca del discurs. El valor que pren una forma verbal determinat dins un enunciat, doncs, està condicionat per aquests altres dispositius.

\section{Disseny i metodologia de la recerca}

Des del punt de vista metodològic, aquest article parteix d'una recerca empírica portada a terme amb una vuitantena d'alumnes de $3 \mathrm{r}$ i 6 è d'educació primària de tres escoles públiques catalanes durant els cursos 2009-2010 i 2010-2011 (Casas, 2012b). L'instrument per a la recollida de dades va consistir en el disseny d'una situació didàctica oral, en parelles, fora de l'aula però dins de l'escola, per promoure la reflexió dels alumnes entorn dels diversos valors del temps verbal del present. En concret, la investigadora conduïa una conversa a partir de la lectura de diversos enunciats que contenien usos del present no prototípics (el prototípic és el que distingeix el present en relació amb el passat i el futur). En aquest article, s'hi presenten només els resultats de les converses sobre el present històric, a partir de les dues frases següents:

- En el segle xv, Colom descobreix Amèrica (frase 1)

- El 1969, l'home arriba a la Lluna (frase 2)

A totes dues frases es posa de manifest la nocoincidència entre el temps de l'enunciat (temps dels fets narrats) i el temps de l'enunciació (temps en què són narrats): el temps de l'enunciat s'expressa a través de dos modificadors temporals ("en el segle Xv" / "el 1969"), mentre que el temps de l'enunciació, mitjançant el temps verbal del present ("descobreix" / "arriba"). A partir de les converses (que es van transcriure, categorit- 
zar i analitzar a través d'una codificació qualitativa), es va poder registrar quins coneixements activaven els alumnes per ancorar temporalment les frases. També es va posar en relleu si hi havia diferències entre les converses de les parelles de $3 \mathrm{r}$ i de 6 è.

\section{Resultats de la recerca}

En aquest apartat s'hi mostren fragments de converses que mantenen les parelles amb la investigadora i que il.lustren la influència del coneixement del món, del coneixement sobre els modificadors temporals i de la seva experiència en el procés per reconèixer el valor retrospectiu del present. $^{2}$

Respecte als modificadors temporals, es mostra un exemple de $3 \mathrm{r}$ i un de 6 è, que es comenten tot seguit:

\section{Fragment 1 (parella 18, 3r; f2)}

30. I: "El 1969 l'home arriba a la Lluna"। Quan passa això/

31. M: És el 1969\ I ara som al 2011\

32. I: Així quan passa això/

33. A: Abans $\backslash$

34. M: Sí, Abans\

Fragment 2 (parella 32, 6è; f1)

14. I: Així - doncs- quan passa aquesta frase/

15. A: En passat \Sí- en passat $\backslash$

16. I: I el verb/Què passa amb el verb/

17. H: Està en present $\backslash$ Descobreix $\backslash$ Si no seria va descobrir o descobriràl

18. I: I dieu que la frase està en passat/ Encara que el verb estigui en present/

19. H i A: Sí

20. I: Per què/

21. H: Perquè el segle Xv és en el passat\

En tots dos exemples anteriors, les parelles ancoren la frase al passat prioritzant el significat dels modificadors temporals. En el fragment 1, la parella de 3r es fixa en la data ("el 1969") i la situa

2 En els fragments que es presenten, $f$ indica 'frase', els torns iniciats amb la lletra I indiquen 'investigadora' i els iniciats per la resta de lletres corresponen a les inicials dels pseudònims dels alumnes. al passat respecte a la data en què es produeix la conversa (2011). En el cas de la frase 1, la parella de 6è reconeix que el verb està en present (en contrast amb el passat i el futur, torn 17) però, tot $\mathrm{i}$ així, atorga preeminència al modificador temporal, és a dir, resol la incompatibilitat entre el temps de l'enunciat i el temps de l'enunciació situant la frase al temps de l'enunciat.

El coneixement dels modificadors temporals també està relacionat amb l'experiència dels alumnes. Lexemple següent posa en relleu que un alumne ancora la data entremig d'un interval experiencial, és a dir, organitza el temps cronològic a partir d'una vinculació experiencial:

Fragment 3 (parella 11, 3r; f2)

6. I: Quan passa això/

7. J: Quan encara no havia nascut la meva mare: $i$ ja havia nascut la meva iaial

8. I: Quan va néixer- la teva mare/

9. J: El 1972\I la meva iaia el 1951\

I en relació amb els modificadors temporals, centrem-nos en la frase 1: al fragment 2 ja hem vist que la parella de 6è resolia que la frase s'ubicava al passat perquè "el segle XV és en el passat" (torn 21). El coneixement sobre els números romans és un aprenentatge escolar, una convenció de datació que els alumnes aprenen a l'àrea curricular de Coneixement del Medi Natural, Social i Cultural. En la recerca es va observar que la presència de números romans a la frase 1 va esdevenir un obstacle per a les parelles de $3 r$ (aquest contingut està situat a cicle superior). Vegem-ho a l'exemple següent, en què l'alumne confon segles amb anys:

Fragment 4 (parella 16, 3r, f1)

6. I: Quan passa això/

7. Q: El 15 del 00:: ai nol

8. I: A quin segle estem- ara/

9. Q: Ara som al segle 2011।

En canvi, fixem-nos en una resposta de 6è, en què l'alumne no solament demostra que coneix la noció de segle, sinó que també activa un altre tipus de coneixement: 
Fragment 5 (parella 38, 6è, f1)

7. R: Fa sis segles:: I sis segles són ((pensa)) sis cops 100 anys $\backslash 600$ anys $\backslash$ I la persona no viu 600 anys \Això és passat\

Finalment, pel que fa al paper del coneixement del món, també s'il.lustra amb la frase 1, i amb un exemple de cada curs, per mostrar fins a quin punt saber qui és el personatge històric (Colom) entorpeix o deslloriga la conversa.

\section{Fragment 6 (parella 5, 3r; f1)}

3. I: Ara que ja hem llegit aquesta frasesabríeu dir quan passa això/

4. T: Què vol dir Colom/

5. V: És un senyor \Un home va viatjar i troba un poble que ningú no ho sabia

6. T: Per exemple el Marroc $\backslash$ I que per exemple mai ha vist:: un:: un colom $\$

Fragment 7 (parella 38, 6è; f1)

40. I: Aquesta frase què és- què díríeu/

41. M: (5) Passat i present $\backslash$ Els dos $\backslash$

42. I: Per què/

43. M: Seria passat- al segle $\mathrm{xv} \backslash$ Però també:: descobreix:: també podríem dir_present_

44. F: Depèn:: depèn de lo que diguis a davant।

45. I: Depèn de què/ Què vols dir/

46. F: Per exemple - si dius Colom - ja saps que fa molt temps:: perquè en Colom ja està mort।

En el fragment 6 (3r), la Tània (T) s'encalla perquè no sap qui (què) és Colom (torn 4 ) i això obstaculitza el raonament posterior, a pesar que el seu company sí que ho sap i intenta explicar el significat de la frase (torn 5). En canvi, al fragment 7 (6è), la Maria (M) dubta entre ubicar la frase al passat o al present, perquè s'adona de la presència de dos elements incompatibles (el modificador temporal i el temps verbal, torns $41 \mathrm{i}$ 43). Amb tot, cal observar que la Fatija (F) apel.la al subjecte de la frase (torn 44), de manera que l'evocació del coneixement cultural que té sobre Colom (que també és un aprenentatge escolar) l'empeny a considerar que la frase s'ancora al passat (torn 46).

\section{Conclusions i implicacions didàctiques}

En aquest article s'ha il-lustrat quins coneixements activen alumnes de $3 \mathrm{r}$ i 6è de primària en una situació didàctica oral en què, en parelles, la investigadora promou la seva reflexió sobre el valor retrospectiu del present. D'entrada cal assenyalar que la interacció (Mercer, 2004) ha permès que els alumnes verbalitzessin les estratègies que mobilitzaven i s'ha posat en relleu la procedència dels seus coneixements. Aquests coneixements no són lingüístics, però podrien ajudar a construir determinats sabers lingüístics (per exemple, els valors dels temps verbals) si es plantegés un ensenyament-aprenentatge més interdisciplinari. En l'article, en concret, s'ha mostrat la confrontació de les parelles al present històric, que és un ús no prototípic del present. Tot i que dels resultats no se'n desprèn que els alumnes hagin reconegut el valor retrospectiu, ${ }^{3}$ el que s'apunta és que els coneixements que han activat es perfilen, amb el guiatge del docent, com una estratègia que pot servir com a punt de partida d'aquest procés.

Per exemple, s'ha constatat que la frase 2 es presta més que no pas la frase 1 a l'ús d'arguments de coneixement del món i experiencials, a causa de la proximitat temporal que expressa el modificador temporal ("el 1969" és una data més recent que "en el segle Xv"). D’altra banda, a la frase 1 s'han detectat rastres d'un coneixement escolar no vinculat a l'assignatura de Llengua Catalana, sinó a la de Coneixement del Medi Natural, Social i Cultural, que és clau per comprendre el modificador temporal ("en el segle Xv"). De fet, hem observat diferències entre $3 r$ i $6 \grave{e ̀ ~ e n ~}$ relació amb l'apropiació del significat d’aquest modificador temporal, que validarien que el coneixement del temps que tenen els nens està mediatitzat pels coneixements culturals i l'aprenentatge escolar (Tartas, 2009).

La influència d'aquest tipus de coneixement ens porta a considerar que, si bé l'ensenyamentaprenentatge del verb és un contingut clarament

\footnotetext{
3 En els fragments escollits per a l'elaboració d'aquest article no s'hi han inclòs les reflexions metalingüístiques dels alumnes, fruit del desenvolupament de les converses, en què prenen consciència que el present no es comporta d'acord amb el valor prototípic i que, per tant, pot expressar altres valors. Vegeu Casas, $2012 b$.
} 
associat a l'assignatura de Llengua, no podem dir el mateix dels temps verbals que, des d'una perspectiva molt diferent a com s'aborda a làrea de Llengua Catalana, té moltes connexions amb la de Coneixement del Medi Natural, Social i Cultural. Si reprenem els continguts curriculars de totes dues àrees, hi observem certes incoherències, tant terminològiques com de seqüenciació. En efecte, com ja s'ha mostrat, les nocions temporals, com abans/després o present/passat/futur són continguts l'aprenentatge dels quals apareix a l'àrea de Coneixement del Medi Natural, Social i Cultural des de cicle inicial de primària. En canvi, en l'àrea de Llengua Catalana, les nocions de passat, present i futur es prescriuen a partir de cicle mitjà. Subratllem, també, com en un cas s'anomenen "nocions bàsiques de temps" (àrea de Coneixement del Medi) i en l'altre, "terminologia gramatical" (àrea de Llengua). Aquestes incoherències no contribueixen a consolidar el coneixement sobre les nocions relacionades amb la temporalitat. S'apunta, doncs, la necessitat de desenvolupar un treball interdisciplinari en l'àmbit escolar per construir el coneixement sobre els temps verbals; sostenim que la comprensió dels temps verbals no se circumscriu únicament a l'assignatura de Llengua, sinó que des d'altres àrees curriculars en què es treballa la temporalitat sembla que es pot donar sentit a la integració entre les formes verbals i els seus usos.

Aquesta recerca ha intentat demostrar que per comprendre un ús verbal (el present històric) cal tenir en compte tant la informació temporal que aporten els altres elements lingüístics de l'enunciat (Klein, 2009) com la resta de coneixements de què disposa l'aprenent, fruit d'altres aprenentatges escolars, del coneixement del món i del coneixement experiencial (Tartas, 2009). Es reclama, doncs, la necessitat que l'escola superi la parcel-lació del coneixement i plantegi l'ensenyament-aprenentatge des d'una perspectiva més holística.

\section{Referències bibliogràfiques}

CAsas, M. (2012a). "La construcció del coneixement sobre el verb en alumnes de $3 \mathrm{r}$ i 6 è d'educació primària" (en línia). Bellaterra Journal of Teaching \& Learning Language \& Literature, 5(2), 43-64. (Data de consulta: 25.08.2014). <http://revistes.uab.cat/jtl3/article/view/462>.

- (2012b). La construcció del coneixement sobre els valors del temps verbal del present a leducació primària. Un estudi de cas sobre l'ús lingüistic, la reflexió gramatical i la interacció en l'ensenyament-aprenentatge de la llengua. Tesi doctoral no publicada. (Data de consulta: 25.08.2014). <http://hdl.handle. net/10803/98339>.

Decret 142/2007, de 26 de juny, pel qual s'estableix l'ordenació dels ensenyaments de l'educació primària. Currículum: educació primària. Servei d'Ordenació Curricular, juny 2009.

Gourdet, P. (2010). "L'enseignement du verbe à l'école élémentaire: caractérisation linguistique et application didactique". Cahiers de l'ED, 139, 17-34.

KLEIN, W. (2009). "How time is encoded", a: W. KLEIN i P. LI. The expression of time. Berlín Nova York: Mouton de Gruyter, p. 39-81.

Lepoire-Duc, S.; Ulma, D. (2010). "Enseigner le verbe en français aujourd'hui: enjeux et tensions". Synergies France, 6, 9-15.

Mercer, N. (2004). "Sociocultural discourse analysis: analysing classroom talk as a social mode of thinking". Journal of Applied Linguistics, 1/2, 137-168.

Perret-Clermont, A. N.; Lambolez, S. (2005). Time, mind, and otherness, a: A. N. Perret-Clermont (coord.). Thinking time. A multidisciplinary perspective on time. Göttingen: Hogrefe \& Huber Publishers, p. $1-12$.

Piaget, J. (1978). El desarrollo de la noción de tiempo en el niño. Mèxic: FCE.

TARTAS, V. (2009). La construction du temps social par l'enfant. Bern: Peter Lang. 